\title{
A Broad Spectral, Interdisciplinary Investigation of the Electromagnetic Properties of Sea Ice
}

\author{
Kenneth C. Jezek, Associate Member, IEEE, Donald K. Perovich, K. M. Golden, Charles Luther, \\ David G. Barber, Prasad Gogineni, Senior Member, IEEE, Thomas C. Grenfell, Associate Member, IEEE, \\ Arthur K. Jordan, Life Fellow, IEEE, Curtis D. Mobley, Son V. Nghiem, Member, IEEE, \\ and Robert G. Onstott, Member, IEEE
}

\begin{abstract}
This paper highlights the interrelationship of research completed by a team of investigators and presented in the several individual papers comprising this Special Section on the Office of Naval Research (ONR), Arlington, VA, Sponsored Sea Ice Electromagnetics Accelerated Research Initiative (ARI). The objectives of the initiative were the following:

1) understand the mechanisms and processes that link the morphological and physical properties of sea ice to its electromagnetic (EM) characteristics;

2) develop and verify predictive models for the interaction of visible, infrared, and microwave radiation with sea ice;

3) develop and verify inverse scattering techniques applicable to problems involving the interaction of EM radiation with sea ice.

Guiding principles for the program were that all EM data be taken with concurrent physical property data (salinity, density, roughness, etc.) and that broad spectral data be acquired in as nearly a simultaneous fashion as possible. Over 30 investigators participated in laboratory, field, and modeling studies that spanned the EM spectrum from radio to ultraviolet wavelengths. An interdisciplinary approach that brought together sea ice physicists, remote-sensing experts (in EM measurements), and forward and inverse modelers (primarily mathematicians and EM theorists) was a hallmark of the program. Along with describing results from experiments and modeling efforts, possible paradigms for using broad spectral data in developing algorithms for analyzing remote-sensing data in terms of ice concentration, age, type, and possibly thickness are briefly discussed.
\end{abstract}

Manuscript received May 20, 1998; revised June 18, 1998. This work was supported by Grants from the Office of Naval Research.

K. C. Jezek is with the Byrd Polar Research Center, Ohio State University, Columbus, OH 43210-1002 USA (e-mail: jezek@ iceberg.mps.ohio-state.edu).

D. K. Perovich is with the U.S. Army Cold Regions Research and Engineering Laboratory, Hanover, NH 03755 USA.

K. M. Golden is with the Department of Mathematics, University of Utah, Salt Lake City, UT 84112 USA.

C. Luther is with the Office of Naval Research, Arlington, VA 22217-5660 USA.

D. G. Barber is with the Department of Geography, University of Manitoba, Winnipeg, Man., R3T2N2 Canada.

P. Gogineni is with the Radar Systems and Remote Sensing Laboratory, University of Kansas, Lawrence, KS 66045 USA.

T. C. Grenfell is with the Department of Atmospheric Sciences, University of Washington, Seattle, WA 98195 USA.

A. K. Jordan is with the Remote Sensing Division, Naval Research Laboratory, Washington, DC 20375 USA.

C. D. Mobley is with Sequoia Scientific, Inc., Mercer Island, WA 98040 USA.

S. V. Nghiem is with the Jet Propulsion Laboratory, California Institute of Technology, Pasadena, CA 91109 USA.

R. G. Onstott is with the Environmental Research Institute of Michigan, Ann Arbor, MI 48107 USA.

Publisher Item Identifier S 0196-2892(98)06692-3.
Index Terms - Electromagnetic (EM) scattering, geophysics, optics, sea ice.

\section{INTRODUCTION}

$\mathbf{T}$ HE ELECTRICAL properties of sea ice growing on the open ocean are determined by its physical state, which is influenced by complex mechanical and thermodynamical forcings of the ocean and atmosphere. Winds, currents, air and water temperatures, and snowfall, among other variables, contribute to the eventual roughness, texture, chemical composition, and temperature gradient through the sea ice, which combine to determine its electromagnetic (EM) signature. These latter properties tend to be inhomogeneous over relatively short length scales (tens of meters horizontally and tens of centimeters or less vertically), and they evolve with time as the boundary conditions and the internal composition of the ice pack change. For these reasons, the analyses of EM data collected by spaceborne instruments over sea ice have tended to rely on empirical relationships between one or more EM variables (for example, brightness temperature) and a geophysical property of the ice. Numerous papers in the literature document the success of this approach for estimating sea ice concentration, type, and motion. Yet for a number of reasons, attempts to obtain a deeper understanding of the EM properties of naturally growing sea ice can be complicated [1]. For example, it is logistically difficult to measure and sample young sea ice, some processes, such as the onset of flooding, are transient phenomena. Inhomogeneity makes sampling difficult and opportunities to view a particular type of ice or even the same piece of ice throughout the seasonal cycle are possible only in areas of landfast sea ice. Individually, almost all of these problems can and have been overcome by investigators in the field. Collectively, however, these problems suggest the need for designing new approaches for answering fundamental questions about sea ice EM properties, namely, what are the important scattering and absorption mechanisms and how are these mechanisms related to ice physical and thermodynamic properties? In turn, they pose new questions about how electrical and physical property relationships change with EM frequency, incidence angle, and polarization.

In 1992, the Office of Naval Research (ONR), Arlington, VA, began a new Accelerated Research Initiative (ARI) en- 


\section{Sea Ice Electromagnetics}
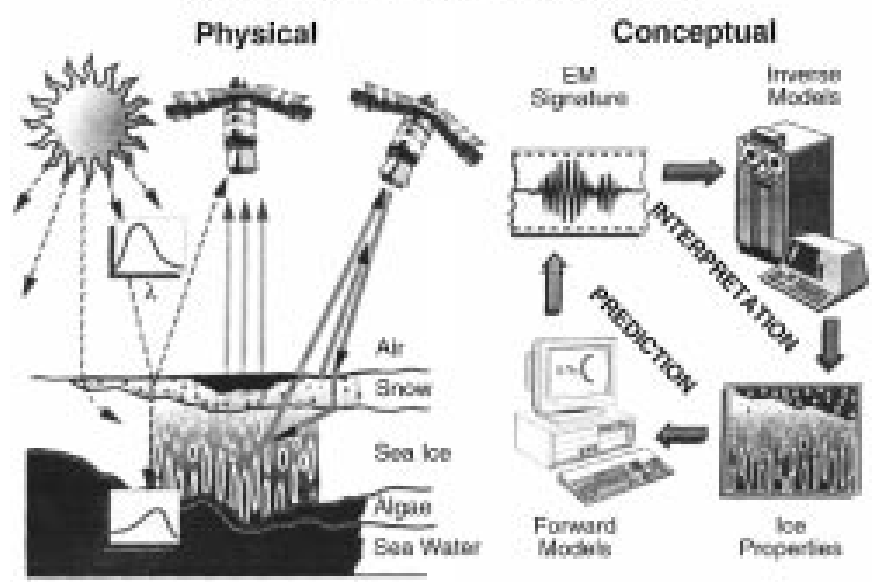

Fig. 1. Conceptual diagram of the ONR ARI. The diagram captures key objectives, including the broad spectral attribute of the ARI and the connections between physical observations, forward modeling, and inverse modeling.

titled "Electromagnetic Properties of Sea Ice." More than 30 investigators from 20 institutions in the United States and Canada participated in the project. The conceptual goal of the initiative is shown schematically in Fig. 1 and on the cover of this issue. Essentially, the program sought to relate the measured EM signature of sea ice to the physical properties of the ice through forward models. In turn, the forward models were used to develop inverse methods through which ice geophysical properties (thickness, roughness, etc.) could be determined from remotely sensed EM data. The ARI had several important attributes that extended it beyond previous studies. First, the range of observations spanned the EM spectrum from the radio band to ultraviolet. Second, simultaneous, broad spectral observations of the same ice samples occurred concurrently with observations of snow and ice physical properties. Third, there was a deliberate effort to more directly involve members of the EM modeling community in the end-to-end experiment design and to purposely include inverse modelers. Fourth, the ARI involved laboratory, field and theoretical components in a unifying process that included careful laboratory observations, field measurements to verify results, and the development of theory and predictive models. Laboratory work extended experiments begun in the 1980's at the United States Army Cold Regions Research and Engineering Laboratory (CRREL), Hanover, NH. Fieldwork validated observations made in the laboratory and increased the range of ice types studied as part of the ARI. Theoretical work aimed at building a model framework for interpreting results and for furthering the basic mathematics of inverse modeling as applied to geophysical problems.

The interdisciplinary nature of the ARI represented both the greatest strength and most significant challenge of the overall effort. Team members included passive and active microwave remote-sensing experts, optical oceanographers, sea ice physicists, and mathematicians, each of whom contributed essential knowledge about the sea ice EM's problem. The challenge was to assemble each piece of knowledge gleaned from across the EM spectrum of interest into a broad spectral model useful for recovering sea ice geophysical properties (snow and ice thickness, thermodynamic state, etc.) from remote-sensing data.

\section{BACKGROUND}

The first series of CRREL experiments (CRRELEX), begun in 1984, was designed to confront some of the difficulties encountered in fieldwork. The CRRELEX approach was to grow sea ice in a carefully constrained laboratory environment where ice physical properties could be manipulated and documented. Microwave experiments were conducted under an umbrella set of conditions that included the following:

1) growth and maintenance of uniform ice sheets of limited and well documented physical properties;

2) use of multiple sensors to collect data simultaneously from the same ice sheet;

3) coordinated interpretation of all the EM observations of the ice with the simultaneously measured ice physical properties.

As the experiments progressed, two more facets were added to the measurement objectives. First, data collection was to be rigorously coupled with particular models and modeling efforts. Second, time-series data were to be collected. This last point arose because observations showed that measurable changes in electrical properties occur at every stage of ice development (Fig. 2).

Experiments completed during the first CRRELEX program demonstrated a capability to grow saline ice with a predefined range of physical properties. These include thin ice with varying crystalline textures and salinity gradients, roughened ice that included a range of roughness elements, desalinated ice and snow-covered ice of various thickness. These data were used to compute the permittivity of thin ice, demonstrate the complex relationship between permittivity and brine migration that occurs as ice grows (the influence of thermal variations), and observe the effect of snow on ice physical and electrical properties. Theoretical work, which concentrated on the microwave part of the spectrum, established frequency bounds on when and under what conditions volume scatter or surface scatter from sea ice dominated the microwave signature.

\section{ARI SCIENCE GOALS}

The ARI built upon previous research by greatly increasing spectral coverage, investigating more ice types and ice growth scenarios, and establishing an inverse modeling component. Research was organized to reach the following four overarching goals:

1) understand the mechanisms and processes that link the morphological/physical and the EM properties of sea ice;

2) further develop and verify predictive models for the interaction of visible, infrared, and microwave radiation with sea ice;

3) develop and verify selected techniques in the mathematical theory of inverse scattering that are applicable to problems arising in the interaction of EM radiation with sea ice; 


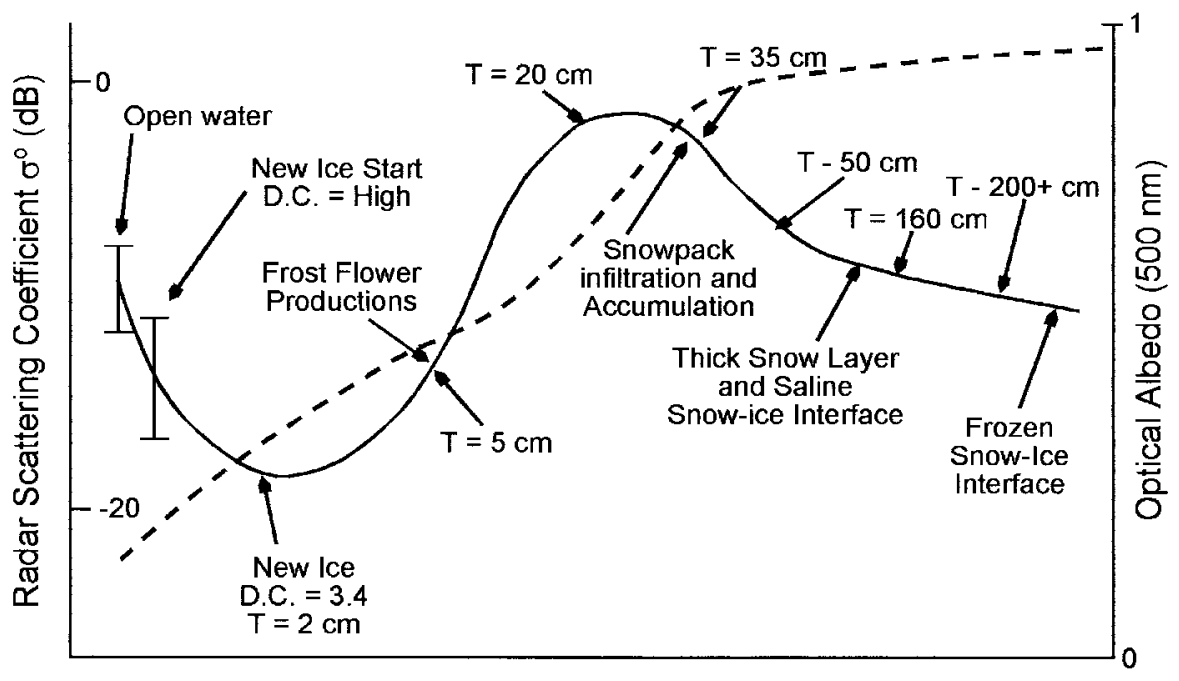

Time

Fig. 2. Qualitative illustration of the time-varying backscatter (solid line) and albedo (dashed line) signature of sea ice throughout its development. A key objective of the ARI was to quantify these relationships across the EM spectrum.

4) use broad spectral data to develop robust spectral models of sea ice EM signatures.

More specific objectives included the following:

1) identify and isolate basic scattering sources and mechanisms (surface, volume) and determine their individual effects on reflection, transmission, and attenuation;

2) quantify sea ice EM properties to unambiguously identify ice types and determine deformation characteristics;

3) measure the influence of snow cover over sea ice on energy reflection, transmission, and absorption;

4) develop physical models of EM forward and inverse scattering from sea ice, which are computationally practicable and applicable to interpretation of remote-sensing data.

\section{APPROACH}

The ARI began in 1992 with laboratory experiments in a vastly upgraded research facility at CRREL. Laboratory research, field studies, and theoretical work continued through 1995. During the last two years of ARI sponsored research, efforts focused on integrating EM and physical properties data sets for concurrent use in model development and verification.

Laboratory experiments were conducted in 1993, 1994, and 1995 in the specially designed Geophysical Research Facility (GRF) at CRREL. The GRF was used by all investigators and provided a common focus for research (Fig. 3). Experiments that required exceptional environmental control were conducted in an indoor laboratory that could be used for careful studies of the effects of changing temperature, humidity, and surface roughness.

A wide range of ice types in various morphological states, snow cover, water, and meteorological conditions, were successfully simulated in the laboratory environment. Most thin ice types, including pancake ice, were studied during the course of these laboratory experiments. As well, studies of the EM/physical property changes during ice growth from open water through thicknesses representing thick first-year ice were accomplished.
The major field component of the ARI was an experiment at Point Barrow, AK, from April 20 to May 10, 1994. The focus of the experiment was to obtain a complete description of the physical and EM properties for thin, first-year, and multiyear ice and snow for verification of laboratory results. Two firstyear sites were studied in detail during the experiment: 1.25m-thick ice in the Chukchi Sea (site 1) and 1.7-m-thick ice in the Beaufort Sea (site 2). In both cases, the ice was snow covered and undeformed. In addition to the contrast in thickness, site 1 had higher level of biota in the ice and greater concentrations of particulates in the snow than site 2. Optical measurements were made of total albedo, spectral albedo, and transmittance $(300-1000 \mathrm{~nm})$, the radiance distribution within the ice and beam spread functions (bsf's) along both vertical and horizontal paths within the ice. Passive and active microwave observations of emissivity and radar backscatter were also made. After observations of the snow-covered ice were completed, the snow was removed and measurements of bare first-year ice were made. Snow and ice cores were collected for later analysis in the laboratory.

Two smaller field experiments occurred in 1995 at Point Barrow and at Resolute Bay, Northwest Territories. The latter was done in close cooperation with the Seasonal Sea Ice Monitoring and Modeling Site (SIMMS) program.

\section{RESUlTS}

Principal results of laboratory experiments, field experiments, and theoretical studies conducted throughout the fiveyear ARI period from 1992 to 1997 are summarized herein.

\section{A. Laboratory Component}

Laboratory experiments conducted as part of the sea ice EM's initiative had three major objectives, as follows:

1) conduct measurements in a controlled environment;

2) conduct measurements that would be difficult to execute in the field; 


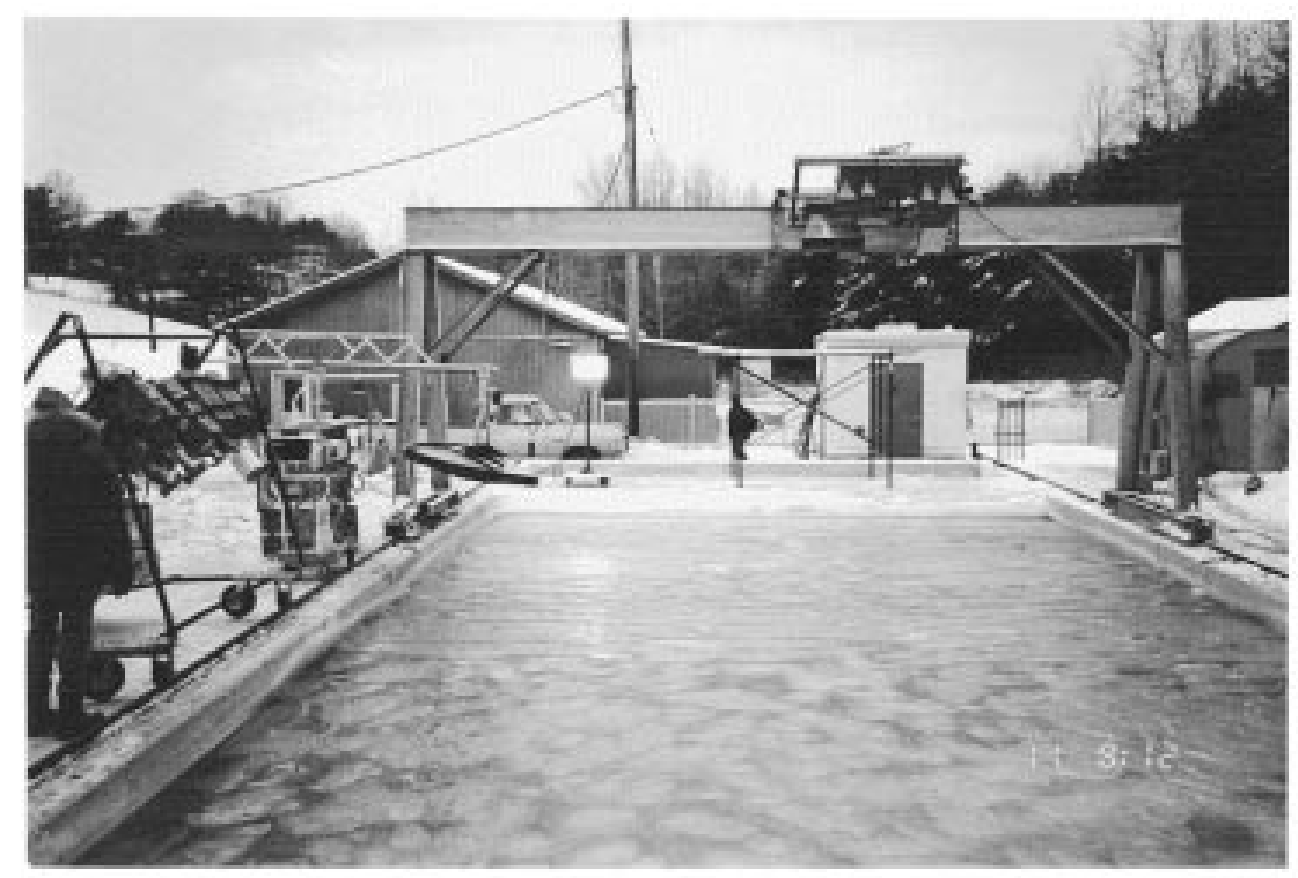

Fig. 3. The sea ice test facility constructed at the CRREL. Pictured is pancake ice, a type of ice that forms in the presence of a wave field. Observations were made from the sides of the pond and from a movable gantry. A removable, refrigerated roof was used to regulate surface conditions, including temperature and the amount of snowfall.

3) bridge laboratory and field measurements through field verification of laboratory results and extend laboratory simulations to a broader range of field environments.

Details of the laboratory experiments are described in several papers [2]-[5]. Highlights include the following:

1) measurements and estimates of dielectric permittivity and index of refraction of sea ice and its components;

2) contributions of microwave volume and surface scattering separated for different incidence angles $\left(0\right.$ to $\left.60^{\circ}\right)$, frequencies (P- to Ka-band) and polarizations;

3) empirical relationships between ice thickness and microwave scatter/emission for thin ice types;

4) transition in microwave polarization ratios from new ice to first-year ice associated with the formation of a low-density surface layer (snow or frost flowers);

5) broad spectral measurements of frost flower and pancake ice signature evolution;

6) strong effect on microwave properties of snow-covered ice and modification of ice surface roughness by brine wicking and brine expulsion;

7) enhancement of C-band backscatter at normal incidence after surface flooding; decrease in backscatter at oblique incidence; copolarization ratios increased after flooding;

8) preferential damping, by sea ice, of ultraviolet radiation relative to photosynthetically active radiation (PAR);

9) correlated changes in optical transmission and microwave backscatter with time-varying evolution of internal ice structure;

10) enhanced sensitivity at optical frequencies to changes in ice freeboard (number density of gas filled inclusions) relative to microwave backscatter;

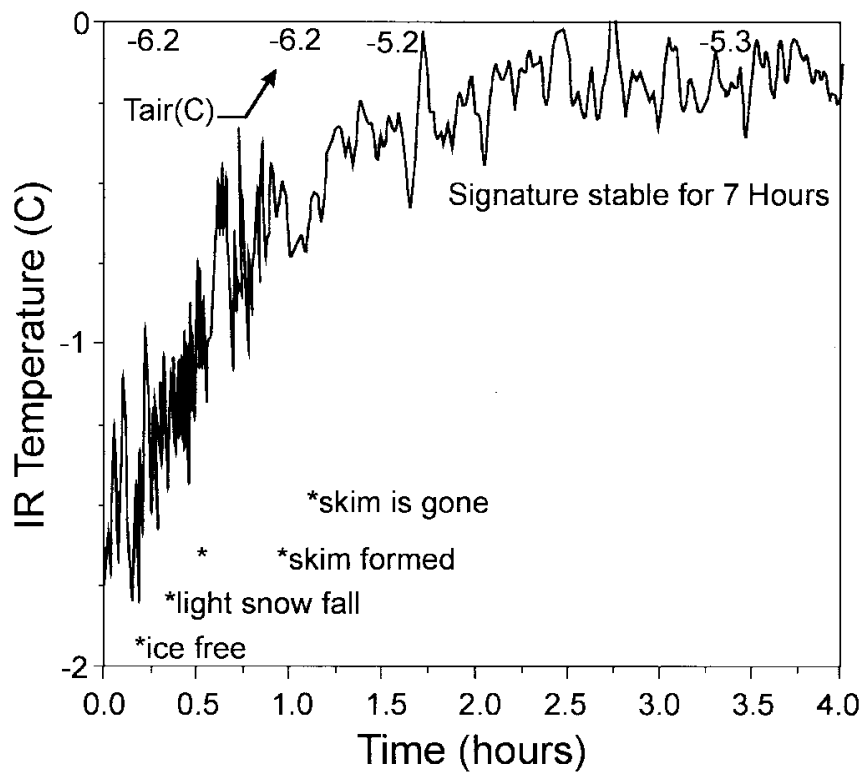

Fig. 4. Plot of pond surface temperatures estimated from thermal-infrared brightness temperatures are plotted with time. Surface changes (ice free, snow fall, ice skim, skim melted) are indicated along with measured air temperatures that remained below $-5{ }^{\circ} \mathrm{C}$ for the entire measurement period.

11) optical frequency sensitivity to changing brine pocket size through increasing transmission loss and albedo with temperature changes. Microwave backscatter increased with temperature because of increased dielectric constant.

Fig. 4 illustrates one of the unique results from the laboratory phase. Thermal infrared measurements were collected during the formation and decay of thin layers of ice on the 


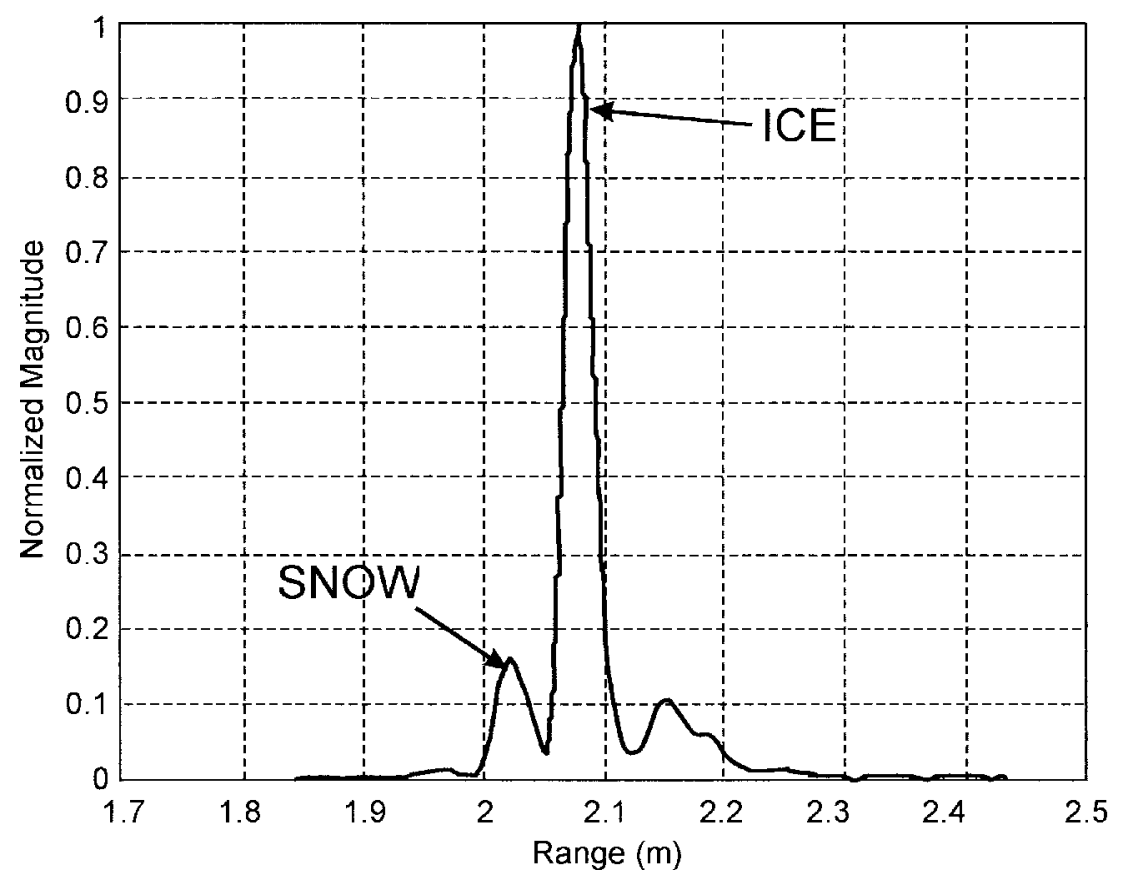

Fig. 5. Wide-band, plane wave normally incident on saline ice covered by a 5-cm-thick snow layer. Range is computed relative to free space.

surface of saline water filling the GRF tank. Because of the calm, stratified condition of the tank, a thin, low-salinity layer formed when snow falling onto the tank melted and after a thin ice skim formed and then melted. We hypothesize that this combination caused the pond to appear warmer than seawater at its melting point and warmer than surrounding materials with temperatures closer to ambient air temperatures. This complicated infrared signature has implications when using remote-sensing data for estimating the surface heat budget and heat flux.

Laboratory work also resulted in several technical advances. These included the first application of plane wave illumination structures for studying microwave backscatter from a distributed target [6], development of ultrawide-band microwave radars, developing techniques for measuring dielectric constants on ice samples in situ, innovative techniques for creating carefully controlled rough surfaces, and construction and application of polarimetric and UHF radiometers. An example of the ultrawide-band radar results is shown in Fig. 5, which illustrates the response of a plane wave normally incident on saline ice covered by a 5 -cm-thick snow layer. The time-domain response is constructed from stepfrequency data collected between 2 and $18 \mathrm{GHz}$. Returns from the snow and ice surfaces are easily resolvable, enabling a separation of scattering contributions from the different constituents. This example demonstrates the dominance of scattering from the snow-ice interface over the air-snow interface for this situation.

\section{B. Field Component}

Field observations were an integral part of the sea ice ARI. The field studies had three broad objectives, as follows:

1) determine if conclusions from the laboratory experiments were confirmed in the field;
2) extend the laboratory work to include additional ice types and conditions;

3) add new experimental techniques and investigate phenomena that could not be studied in the laboratory.

Results of the field studies are summarized in [7], with details available in individual reports [8]-[11]. Significant results from the field program include the following.

1) First-ever in situ measurements of light scattering parallel and perpendicular to oriented ice crystals showed effects of ice morphology on optical properties.

2) Size distribution of air bubbles can be described by a two-parameter log normal distribution.

3) Presence of particulates in the surface layer of sea ice reduces albedo and increases absorption.

4) In-ice radiance distribution is strongly influenced by particulates and dissolved materials in the ice.

5) Stokes vector of reflected light increases in the plane of incidence of the solar beam, most notably for smooth surfaces, such as melt ponds and bare ice.

6) As the snow cover melts away, the average albedo decreases and the horizontal variability in albedo increases.

7) Visible-wavelength albedos for melt pond are influenced by pond depth, the structure of the underlying ice, and the presence of particulates.

8) Anisotropic microwave permittivity caused by brine pocket asymmetry in columnar ice.

The field program complemented the laboratory experiments and enabled the entire cycle of first-year ice from initial growth to the onset of melt to be examined. Measurements of initial ice growth were made in the laboratory, where controlled conditions and easy access to the thin ice were major advantages. The temporal evolution of sea ice physical and EM properties during the spring-summer transition for thick first-year ice $(1.6 \mathrm{~m})$ were investigated in the field. 

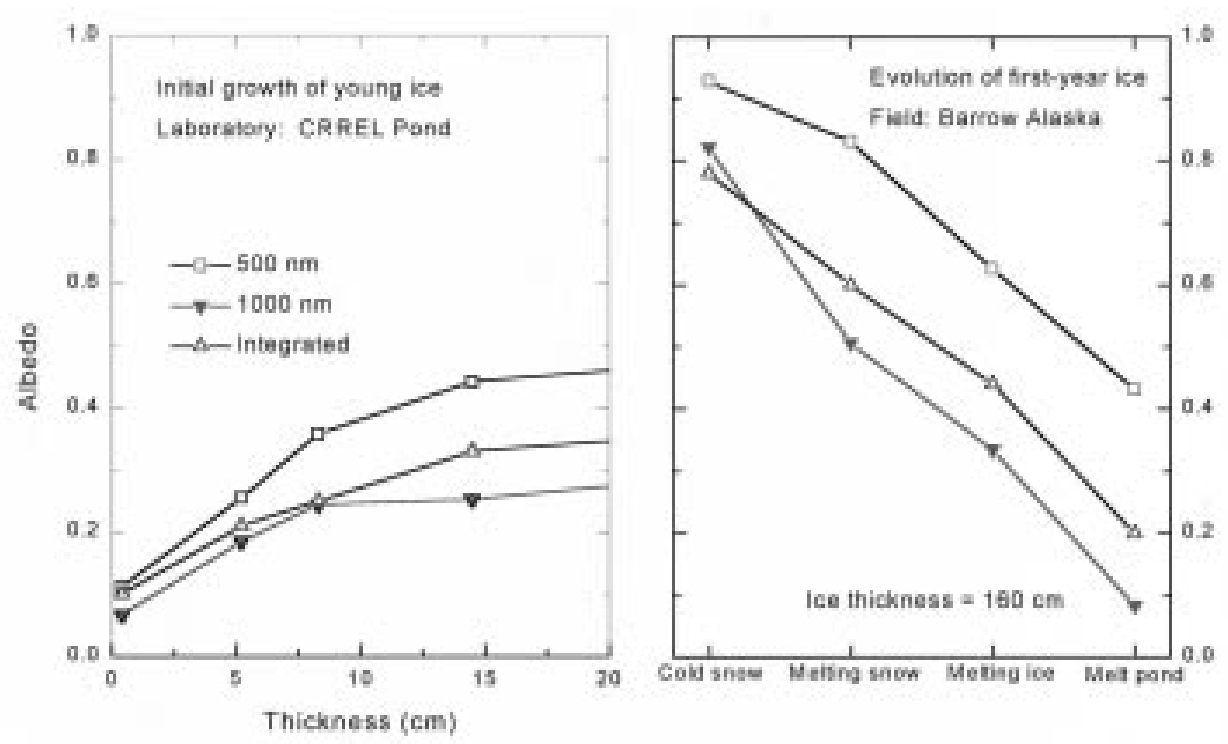

Fig. 6. Compilation of laboratory and field observations showing the evolution of albedo during the initial growth of young ice and during the seasonal transition from spring to summer. Results are presented for 500 and $1000 \mathrm{~nm}$, and spectral albedos at 500 and $1000 \mathrm{~nm}$ are plotted as well as values integrated over the solar spectrum from 300 to $3000 \mathrm{~nm}$.

Fig. 6 illustrates the synergy between the laboratory and field studies. Albedos at $500 \mathrm{~nm}, 1000 \mathrm{~nm}$, and those integrated over the solar spectrum (300-3000 $\mathrm{nm})$ are plotted for initial ice growth and for the transition from snow-covered ice to melt ponds. Scattering coefficients for snow and ice are roughly comparable at 500 and $1000 \mathrm{~nm}$, but the absorption coefficient at $1000 \mathrm{~nm}$ is more than two orders of magnitude greater. Because of this, the relative contribution of volume scattering is much greater at $500 \mathrm{~nm}$. Albedos at $1000 \mathrm{~nm}$ are determined primarily by conditions in the top few centimeters of the medium, while deeper levels make a contribution at $500 \mathrm{~nm}$.

New optical techniques were developed for measuring bsf's over a full $360^{\circ}$ in angle, and as a function of depth, along horizontal paths in the ice. Such measurements provide a new tool for understanding the relationships between ice physical and optical properties. In particular, horizontal bsf measurements, which are made between coring holes drilled in the ice, can provide important constraints on inverse algorithms for retrieving ice properties, such as scattering phase functions, that are difficult to measure directly.

The combination of field and laboratory studies contributed to knowledge about microwave backscatter from snowcovered ice. The thermodynamic behavior of the snow-ice interface, along with snow thickness and grain properties, turns out to be an important control on overall scattering strength. Earlier laboratory work [12], [13] at $13.9 \mathrm{GHz}$ showed that interface wetness either due to brine wicking or flooding increased backscatter by many decibels. The combination of interface roughness and increased dielectric constant explained the observation. Fieldwork [14] demonstrated that there was much less of an effect at C-band because the longer wavelength signal responded less to the interface roughness. In fact, backscatter from dry snow-covered ice was a slightly stronger scatter than flooded ice. An even larger damping of backscatter (4-8 dB decrease) was observed during the ARI [15] when a new ice surface was flooded with saline water. Wide-band radar data acquired during the ARI support these observations and suggest the crossover in dominant scattering mechanisms occurs between 9 and $10 \mathrm{GHz}$ for new snow on new ice [3], [4]. Above the crossover frequency, the signal responds to the presence of snow because scattering is increased by both snow thickness and interface wetness. These results suggest that radars operating above $9 \mathrm{GHz}$ are better suited to studies of both the interface and volumetric properties of snow-covered ice.

Complementary measurements were conducted as part of the Canadian led SIMMS [16]. The field experiment extended the range of ARI ice types to include ice types, with a focus on snow cover, typical of the Canadian high arctic. An important outcome of this experiment was the demonstration that microwave scattering over thick first-year sea ice was affected by the thermodynamic state of the snow-ice system [17]. The degree to which scattering and other wave propagation phenomena are effected is specific to certain ranges of salinity, surface roughness, snow thickness, grain sizes, wetness, and thickness of sea ice. The greatest thermal modulation occurs for thick, smooth first-year sea ice, and the least thermal modulation occurs over multiyear, thin, smooth first-year $(<40$ $\mathrm{cm}$ ), or rough forms of first-year sea ice. Related modeling studies suggest that it is possible to correlate temporal changes in microwave backscatter with changes in temperature [18] and spatial changes in snow thickness [19].

\section{Theory Component}

The goal of theoretical research conducted under the ARI was to develop techniques for using remotely sensed data on the EM fields scattered or emitted by sea ice to deduce the physical properties of the sea ice pack (Fig. 7). To achieve this goal, theoretical models, both forward and inverse, were devel- 


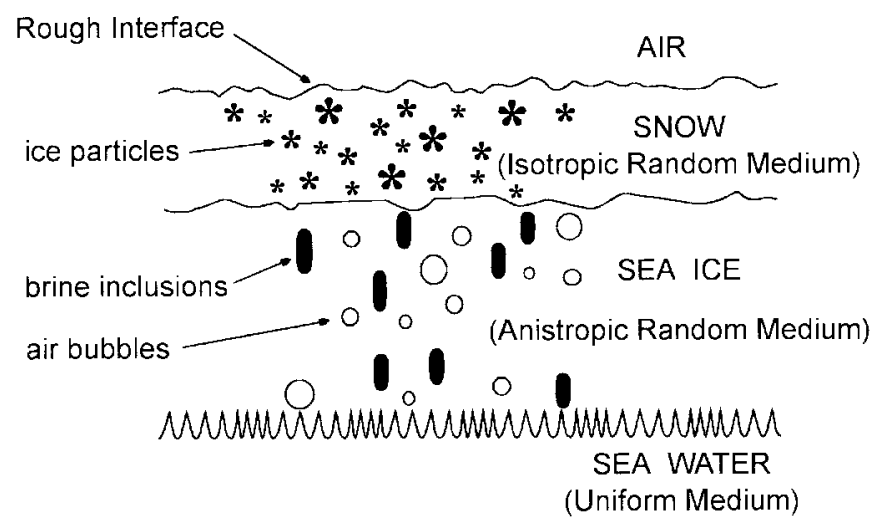

Fig. 7. Illustration of the structural components of sea ice incorporated into modeling studies. In the general case, snow cover of varying composition is taken to overlay rough sea ice. The sea ice is composed of submillimeter-sized brine inclusions and air bubbles. The lower boundary of the congelation ice depicted here consists of small ice dendrites protruding into the sea water.

oped to address these physical properties from the microwave to the optical parts of the spectrum. Parameters included in the forward models, some of which can be deduced from the inverse models, are illustrated in Fig. 7. Mobley et al. [20] discuss progress on interpretation of observations across the optical portion of the spectrum. Golden et al. [21], [22] discuss general forward and inverse models that are applicable to the interaction of EM waves with complex random media, but that are particularly suited to the microwave region for applications to sea ice.

Analyses of optical data show that classical radiative transfer theory is adequate for predicting visible wavelength albedos, transmittances, and bsf's. It was also shown that it is possible to begin with ice physical properties, such as brine pocket and bubble size distributions, and predict ice scattering and absorbing properties. When used in radiative transfer models, the results lead to predicted albedos, transmittances, and bsf's that are in agreement with observations. Bsf's measured along horizontal paths within the ice provided an important test of the scattering properties of sea ice, as predicted from first principles.

The limitations of classical photon diffusion theory for modeling light propagation in sea ice were investigated by Mobley and Maffione [23]. They found that, although diffusion theory gives reasonably accurate predictions of light propagation deep in the interior of thick sea ice layers, boundary effects preclude the use of diffusion theory for predicting the albedo of, or transmittance through, ice sheets. More importantly, diffusion theory shows that the average cosine $g$ of the scattering angle in sea ice must be very near one. This important constraint on $g$ is consistent with predictions based on Mie theory [20].

Research in the microwave portion of the spectrum has resulted in the generation of robust forward scattering models; new developments in the mathematical theory of inverse scattering models, particularly for one-dimensional (1-D) layered media; as well as the mathematical theory of homogenization, which relates the microstructural features of sea ice to its effective EM behavior. Significant refinements in approximate calculations of EM scattering from sea ice have also resulted. In conjunction, these advances have led to stable algorithms for recovering permittivity profiles, brine volume, and other microstructural information [22].

Microwave experiment and theory focused on limiting assumptions of radiative transfer theory versus dense-medium models of radiative transfer. Observations showed that the density of scatterers in sea ice is more than one inclusion per cubic millimeter for brine pockets [24]. Each brine pocket presents a huge dielectric contrast with respect to ice, but fortunately the inclusions are small in the near-surface layers of the ice examined. Consequently, the brine inclusions cannot, in general, scatter microwaves independently of one another, and a dense-medium approach is required. If classical radiative transfer is used at microwave wavelengths, there must be some ad hoc compensating factor to produce volume scattering at the proper level.

Several combined theoretical and experimental studies attempted to identify microwave scattering contributions from the surface and from the volume of the thin and first-year ice studied during the ARI. Scattering from very smooth ( $\mathrm{rms}$ surface roughness less than $0.05 \mathrm{~cm}$ ) ice was considered in several investigations [25], [26]. For frequencies above $13 \mathrm{GHz}$, analyses suggested that surface scattering dominated for incidence angles greater than $50^{\circ}$. At higher frequencies $(17 \mathrm{GHz})$, the surface scattering dominates for angles less than about $25^{\circ}$ [27]. Surface scattering was also found to be the dominant mechanism on first-year ice observed at Point Barrow. Volume scattering was observed to become increasingly more important as the ice drained, as demonstrated by laboratory experiments that artificially elevated the ice surface above the freeboard [5]. During the experiment, brine was replaced by air pockets replicating the first stages of the conversion of first-year ice to multiyear ice, in which volume scatter does dominate.

It is difficult to draw general conclusions about scattering mechanisms from these case studies because ice physical properties are highly variable and, in several cases, measurement accuracies are difficult to assess. An alternative approach investigated as part of the ARI is to use a processoriented method with time-series data (sea ice growth, diurnal effects) to analyze the scattering mechanisms. In a given process, sea ice parameters are interrelated and governed by ice physics, which determine the level and temporal trend of the backscatter. Constrained by the physical trends, the scattering mechanisms can be identified depending on the resulting changes in roughness or volume parameters that cause the corresponding backscatter to increase or decrease.

An example of process-oriented modeling explored during the ARI is illustrated in Fig. 8. C-band backscatter signatures were measured as sea ice grew and experienced diurnal thermal cycling [28]. Ice growth started in the early afternoon when insolation was high [lower panel in Fig. 8(a)]. The ice sheet cooled into the evening and the following night. Diurnal cycling occurred over two days, during which the ice sheet grew by $10 \mathrm{~cm}$. Temperature cycling caused brine volume to change [upper panel in Fig. 8(a)] according to the eutectic phase distribution [29], forcing brine pocket size to increase and decrease by wall melting and freezing. Furthermore, complex permittivities of the sea ice constituents (ice and 


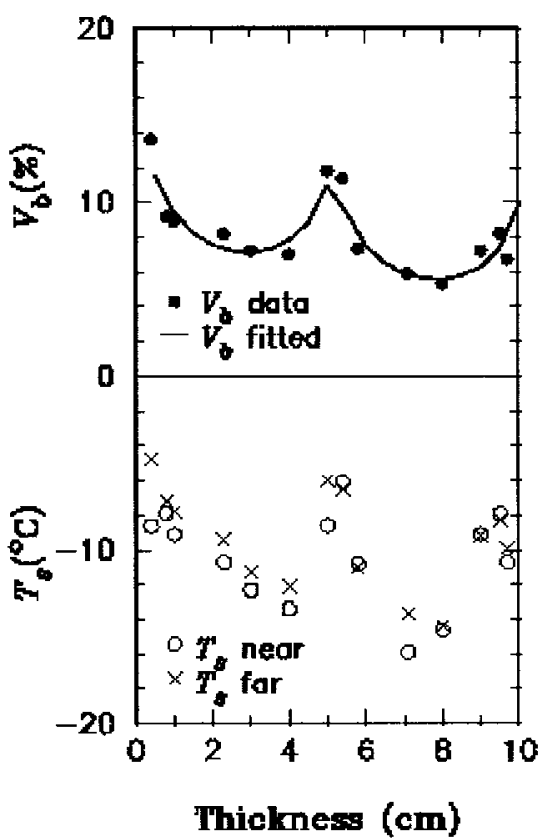

(a)

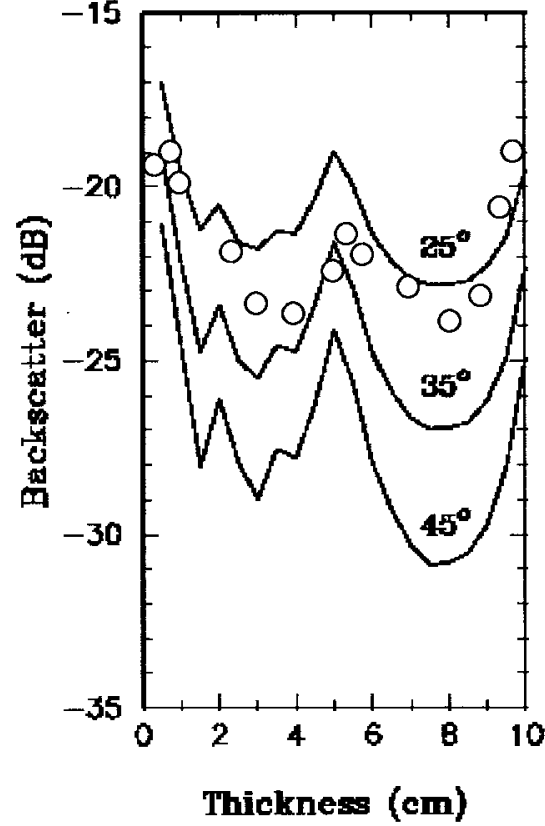

(b)

Fig. 8. (a) Sea ice surface temperature $T_{s}$ measured near the area of the radar footprints and at the far side of the sea ice sheet, and the brine volume $V_{b}$ corresponding to the temperature cycles. (b) Backscatter calculated at $\mathrm{HH}$-polarization and 25,35 , and $45^{\circ}$ incidence angles for the ice properties depicted in (a). Circles are measured HH-polarization backscatter data for $25^{\circ}$ incidence [28].

brine) varied cyclically with the temperature variations. These interrelated processes caused the backscatter signature to cycle, as observed in the experiment [28] and confirmed by modeling.

Fig. 8(b) presents model results at 25,35 , and $45^{\circ}$ incidence angles (see [28] for parameters used). At $25^{\circ}$, weak backscatter cycles suggest an important contribution from rough surface scattering, which is not very sensitive to the thermal changes. At 35 and $45^{\circ}$, stronger backscatter cycles indicate a larger contribution from volume scattering, which is very sensitive to the thermal variations that change brine volume and pocket size. Furthermore, the model results capture the underlying decreasing trend due to the desalination process taking place during the ice growth [compare top of Fig. 8(a) with 8(b)]. In view of inverse scattering models, the retrieval of sea ice geophysical parameters, such as thickness, is more successful when the remote-sensing observations are sensitive to the ice growth process [25], [30].

\section{CONCLUSIONS AND IMPLICATIONS}

The ARI demonstrated how a broad-spectrum, interdisciplinary approach could be applied to studying the relationships between sea ice physical and EM properties. As a consequence, the ARI improved our ability to interpret remotesensing data in terms of different sea ice types and for estimating ice thickness [25], [30] as well as other geophysical parameters [31].

There is a more general implication owing to the struggle to marry the efforts of a diverse group of investigators. By expanding discipline-specific research objectives, overcoming limitations in terminology, understanding a wider range of measurement and analysis techniques, and establishing overarching physical objectives, it was possible to construct a rich experimental and theoretical program. The results of the program contribute to the groundwork for interpreting data from next-generation sensors capable of observing earth's ice cover in exceptional spectral, temporal, and spatial detail.

\section{REFERENCES}

[1] F. D. Carsey, Ed., Microwave Remote Sensing of Sea Ice. Washington DC: Amer. Geophys. Union, Mono. 68, 1992.

[2] T. C. Grenfell, D. G. Barber, A. K. Fung, A. J. Gow, K. C. Jezek, E. J Knapp, S. V. Nghiem, R. G. Onstott, D. K. Perovich, C. S. Roesler, C. T. Swift, and F. Tanis, "Evolution of electromagnetic signatures of sea ice from initial formation to the establishment of thick first-year ice," this issue, pp. 1642-1654.

[3] R. G. Onstott, P. Gogineni, A. J. Gow, T. C. Grenfell, K. C. Jezek, D. K. Perovich, and C. T. Swift, "Electromagnetic and physical properties of sea ice formed in the presence of wave action," this issue, pp. $1764-1783$.

[4] D. G. Barber, A. K. Fung, T. C. Grenfell, S. V. Nghiem, R. G. Onstott, V. I. Lytle, D. K. Perovich, and A. J. Gow, "The role of snow on microwave emission and scattering over first-year ice," this issue, pp. $1750-1763$.

[5] F. J. Tanis and R. G. Onstott, "Laboratory study of electromagnetic properties of saline ice during ice growth, temperature cycling, and freeboard conditions," IEEE Trans. Geosci. Remote Sensing, to be published.

[6] S. Gogineni, K. C. Jezek, L. Peters, J. D. Young, S. G. Beaven, and E. M. Nassar, "Application of plane waves for accurate measurement of microwave scattering from geophysical surfaces," IEEE Trans. Geosci. Remote Sensing, vol. 33, pp. 627-633, May 1995.

[7] D. K. Perovich, J. Longacre, D. G. Barber, G. F. R. A. Maffione, Cota, C. D. Mobley, A. J. Gow, R. G. Onstott, T. C. Grenfell, W. S. Pegau, M. Landry, and C. S. Roesler, "Field observations of the electromagnetic properties of first-year sea ice," this issue, pp. 1705-1715.

[8] A. J. Hunt, D. Miller, M. S. Quinby-Hunt, "Polarization-dependent measurements of sea ice," in Proc. SPIE 2258, Ocean Opt. XII, J. S. Jaffe, Ed. 1995, pp. 613-622.

[9] R. A. Maffione and C. D. Mobley, "Theory and measurements of the complete beam spread function of sea ice," Limnol. Oceanogr., to be published

[10] D. K. Perovich, C. S. Roesler, and W. S. Pegau, "Variability in sea ice optical properties," J. Geophys. Res., to be published. 
[11] C. S. Roesler and R. Iturriaga, "Absorption properties of marine-derived material in Arctic sea ice," in Proc. SPIE, Ocean Opt. 12, Int. Soc. Opt. Eng., vol. 2258, pp. 933-943, 1994

[12] V. I. Lytle, K. C. Jezek, S. Gogineni, and A. Hosseinmostafa, "Field observations of microwave backscatter from Weddell sea ice," Int. J. Remote Sensing, vol. 17, no. 1, pp. 167-180, 1996.

[13] V. I. Lytle, K. C. Jezek, A. R. Hosseinmostafa, and S. P. Gogineni, "Laboratory Backscatter measurements over Urea ice with a snow cover at Ku band," IEEE Trans. Geosci. Remote Sensing, vol. 31, pp. 1009-1016, Sept. 1993.

[14] A. R. Hosseinmostafa, V. I. Lytle, K. C. Jezek, S. P. Gogineni, S. F. Ackley, and R. K. Moore, "Comparison of radar backscatter from Antarctic and Arctic sea ice," J. Electromagn. Waves Applicat., vol. 9, no. 3, pp. 421-438, 1995 .

[15] R. Kwok, S. V. Nghiem, S. Martin, D. P. Winebrenner, A. J. Gow, D. K. Perovich, C. T. Swift, D. G. Barber, K. M. Golden, and E. J. Knapp, "Laboratory measurements of sea ice: Connections to microwave remote sensing," this issue, pp. 1716-1730.

[16] E. F. LeDrew and D. G. Barber, "The SIMMS program: A study of change and variability within the marine cryosphere," Arctic, vol. 47 no. 3, pp. 256-264, 1994.

[17] D. G. Barber and A. Thomas, "The influence of cloud cover on the radiation budget, physical properties, and microwave scattering coefficient of first-year and multiyear sea ice," IEEE Trans. Geosci. Remote Sensing, vol. 36, pp. 38-50, Jan. 1998.

[18] S. V. Nghiem, R. Kwok, J. A. Kong, R. T. Shin, S. A. Arcone, and A. J. Gow, "An electrothermodynamic model with distributed properties for effective permittivities of sea ice," Radio Sci., vol. 31, no. 2, pp. 297-311, 1996

[19] D. G. Barber and S. V. Nghiem, "On the estimation of snow thickness distributions over sea ice using active microwave scattering," submitted for publication.

[20] C. D. Mobley, G. F. Cota, T. C. Grenfell, R. A. Maffione, W. S. Pegau, and D. K. Perovich, "Modeling light propagation in sea ice," this issue, pp. 1743-1749.

[21] K. M. Golden, M. Cheney, K.-H. Ding, A. K. Fung, T. C. Grenfell, D. Isaacson, J. A. Kong, S. V. Nghiem, J. Sylvester, and D. P. Winebrenner, "Forward electromagnetic scattering models for sea ice," this issue, pp. $1655-1674$.

[22] K. M. Golden, D. Borup, M. Cheney, E. Cherkaeva, M. S. Dawson, K.-H. Ding, A. K Fung, D. Isaacson, S. A. Johnson, A. K. Jordan, J. A. Kong, R. Kwok, S. V. Nghiem, R. G. Onstott, J. Sylvester, D. P. Winebrenner, and I. H. H. Zabel, "Inverse electromagnetic scattering models for sea ice," this issue, pp. 1675-1704.

[23] C. D. Mobley and R. A. Maffione, "The utility of first-order diffusion theory for modeling light propagation in sea ice," submitted for publication

[24] D. K. Perovich and A. J. Gow, "A quantitative description of sea ice inclusions," J. Geophys. Res., vol. 101, no. C8, pp. 18 327-18 343, 1996.

[25] I. H. H. Zabel, K. C. Jezek, S. P. Gogineni, and P. Kanagaratnam, "Search for proxy indicators of young sea ice thickness," J. Geophys. Res., vol. 101, no. C3, pp. 6697-6709, 1996.

[26] S. G. Beaven, G. L. Lockhart, S. P. Gogineni, K. C. Jezek, A. R. Hosseinmostafa, A. J. Gow, D. K. Perovich, A. K. Fung, and S. Tjuata, "Laboratory measurements of radar backscatter from bare and snowcovered saline ice sheets," Int. J. Remote Sensing, vol. 16, no. 5, pp. 851-876, 1995

[27] J. Bredow, A. K. Fung, R. Porco, R. Hosseinmostafa, K. C. Jezek, L. Peters, J. Young, and A. J. Gow, "An experimental study of relative contributions from surface and volume scattering mechanisms in saline ice," in Proc. IGARSS'94, Pasadena, CA, vol. 1, pp. 608-610.

[28] S. V. Nghiem, R. Kwok, S. H. Yueh, D. K. Perovich, A. J. Gow, C. C. Hsu, K.-H. Ding, J. A. Kong, and T. C. Grenfell, "Diurnal thermal cycling effects on backscatter of thin sea ice," IEEE Trans. Geosci. Remote Sensing, vol. 36, pp. 111-124, Jan. 1998.

[29] G. F. N. Cox and W. F. Weeks, "Equations for determining the gas and brine volumes in sea-ice samples," J. Glaciol., vol. 29, no. 12, pp. 306-316, 1983

[30] S.-E. Shih, K.-H. Ding, S. V. Nghiem, C.-C. Hsu, J. A. Kong, and A. K. Jordan, "Thin saline ice thickness retrieval using time series C-band polarmetric radar measurements," this issue, pp. 1731-1742.
[31] R. J. Adams and G. S. Brown, "A model for altimeter returns from penetrable geophysical media," this issue, pp. 1784-1793.

Kenneth C. Jezek (A'92), photograph and biography not available at the time of publication.

Donald K. Perovich, for a photograph and biography, see p. 124 of the January 1998 issue of this TRANSACTIONS.

K. M. Golden, photograph and biography not available at the time of publication.

Charles Luther, photograph and biography not available at the time of publication.

David G. Barber, for a photograph and biography, see p. 50 of the January 1998 issue of this Transactions.

Prasad Gogineni (S'75-M'76-SM'91), photograph and biography not available at the time of publication.

Thomas C. Grenfell (M'94-A'95), for a photograph and biography, see p. 124 of the January 1998 issue of this Transactions.

Arthur K. Jordan (M'50-SM'74-F'91-LF'96), for a photograph and biography, see this issue, p. 1631.

Curtis D. Mobley, photograph and biography not available at the time of publication.

Son V. Nghiem (M'86), for a photograph and biography, see p. 123 of the January 1998 issue of this TRANSACTIONS.

Robert G. Onstott (S'73-M'79), photograph and biography not available at the time of publication. 